\title{
A SUPPRESSOR OF LEUCINELESS IN SALMONELLA TYPHIMURIUM
}

\author{
P. F. SMITH-KEARY \\ Department of Genetics, Trinity College, Dublin
}

Received 27.ii.59

\section{INTRODUCTION}

IN experiments which were designed to measure the rate of mutation of a leucine auxotroph of Salmonella typhimurium to prototrophy it was found that the apparent " reversions " were of three types. These were distinguishable by their growth rates in the absence of leucine. This paper presents an analysis of one of these " reversions " which has a slower growth rate in the absence of leucine than the wild type.

\section{TERMINOLOGY, MATERIALS AND METHODS}

The terminology and nomenclature used is that described by Demerec (1956). The symbol for each mutant is an abbreviation of the nutritional requirement involved: try, requires tryptophane; me, requires methionine; leu, requires leucine ; ara, unable to utilise arabinose. Similar mutants of independent origin are distinguished by numbers, assigned to the mutants in the order in which they are found. When the locus of the mutant allele is known, a capital letter designating that locus is included in the symbol for the mutant; e.g. $\operatorname{try} B-2$. The symbol for a suppressor gene includes an abbreviation of the mutant character it suppresses together with an identifying number; e.g. su-leu-I is the first isolated suppressor of leucine requirement. Symbols for wild type alleles are omitted except where ambiguity may arise, when the symbol for the mutant allele with a superscript plus sign is used.

The triple auxotrophs $l e u-\mathrm{I} 5 \mathrm{I}, m e A-22, \operatorname{try} B-2$ and $l e u-\mathrm{I} 52, m e A-22, \operatorname{try} B-2$ were obtained from the double auxotroph $m e A-22, \operatorname{try} B-2$ by irradiation with ultra-violet light followed by penicillin screening. The double mutant leu-39, ara-9 was obtained from the Cold Spring Harbor collection. All the stocks used were $S$. typhimurium strain LT-2.

Temperate phage PLT-22 was used in all transduction experiments.

Cultures were grown in I per cent. Difco nutrient broth and assayed on 2.55 per cent. Difco nutrient agar. The minimal media (MM) and enriched minimal media (EMM) were those of Yura (1956) with the addition of 0.002 per cent. of methionine and of tryptophane. Leucine supplemented media (MM+L and $\mathrm{EMM}+\mathrm{L}$ ) contained in addition 0.002 per cent. $d l$-leucine. For EMB agar, 0.04 per cent. eosin, 0.006 per cent. methylene blue and $\mathrm{I} \cdot 0$ per cent. arabinose were added to 2.55 per cent. nutrient agar.

$\mathrm{T}_{2}$ buffer contained $\mathrm{KH}_{2} \mathrm{PO}_{4} \mathrm{O} \cdot \mathrm{I}_{5}$ per cent., $\mathrm{NaCl} 0.4$ per cent., $\mathrm{K}_{2} \mathrm{SO}_{4} \mathrm{O} \cdot 5$ per cent., $\mathrm{Na}_{2} \mathrm{HPO}_{4} \mathrm{O} \cdot 3$ per cent., $\mathrm{MgSO}_{4}$ 0.0I 2 per cent., $\mathrm{CaCl}_{2}$ o.oo I I per cent. and gelatin $0 \cdot 00 \mathrm{I}$ per cent.

\subsection{Preparation of phage}

The donor strain was grown for $24 \mathrm{hr}$. on a nutrient agar slope and the bacteria washed off in $5 \mathrm{ml}$. of I per cent. nutrient broth. Equal volumes of this suspension and a phage suspension with a titre of approximately $10^{8}$ particles $/ \mathrm{ml}$. were mixed and stood for $8 \mathrm{~min}$. to allow for adsorption of the phage, after which $\mathrm{O} \cdot \mathrm{I} \mathrm{ml}$. samples 
of the mixture were added to 5 tubes, each containing 2-3 $\mathrm{ml}$. of sterile $0 \cdot 7$ per cent. molten agar at $37^{\circ}$. The contents of each tube were shaken and poured over the surface of a nutrient agar plate. After the plates had been incubated for $24 \mathrm{hr}$. the sloppy agar was scraped off, shaken up in $\mathrm{I}_{5} \mathrm{ml}$. of $\mathrm{T}_{2}$ buffer and stood for $2 \mathrm{hr}$. The bacterial debris and agar were removed by centrifuging, and the supernatant sterilised by shaking with $\mathrm{I}-2 \mathrm{ml}$. of chloroform. The preparation was stored at $4^{\circ}$ until required, when air was bubbled through until all the chloroform had evaporated.

The phage preparations were assayed by the agar layer technique (Adams, 1950). Using the above method yields of $\mathrm{I}_{-4} \times \mathrm{IO}^{11}$ particles $/ \mathrm{ml}$. are obtained when a sensitive donor is used. With a lysogenic donor the yield is $10^{7}-10^{8}$ particles/ml.

\subsection{Transduction}

Bacteria from overnight broth cultures of the recipient were washed twice and suspended in $\mathrm{T}_{2}$ buffer. These suspensions had a titre of $2-3 \times 1 \mathrm{I}^{9}$ bacteria/ml. The high titre phage preparations were diluted in $\mathrm{T}_{2}$ buffer to a titre of $2-3 \times 10^{10}$ particles $/ \mathrm{ml}$. and $\mathrm{I} \mathrm{ml}$. of this dilution added to $\mathrm{I} \mathrm{ml}$. of the suspension of the recipient, giving a multiplicity of infection of $\mathrm{s}$. After standing for $9 \mathrm{~min}$. to allow the phage to be adsorbed, $o^{\cdot} \mathrm{I} \mathrm{ml}$. samples of the transduction mixture were spread on EMM. When a high frequency of transduction was expected, a $10^{-1}$ dilution of the transduction mixture was also plated. The controls, to determine the frequency of spontaneous mutations, were $(a)$ I $\mathrm{ml}$. of recipient plus $\mathrm{I} \mathrm{ml}$. of $\mathrm{T}_{2}$ buffer and $(b) \mathrm{I} \mathrm{ml}$. of recipient plus $\mathrm{I} \mathrm{ml}$. of homologous phage. The total numbers of viable bacteria in the transduction mixtures and controls were determined by diluting appropriately and plating on nutrient agar.

With the low titre phage preparations the same method was used except that the suspension of the recipient was diluted $\mathrm{I}$ in 40 or $\mathrm{I}$ in 80 , and the phage preparation was used undiluted.

All plates were scored after three days' incubation at $37^{\circ}$.

\subsection{Testing of clones}

A proportion of the clones which arose by transduction and by mutation were tested to determine their growth rates in the presence and absence of leucine. Clones were shaken in saline, diluted and plated on MM and MM+L. The plates were examined after 24 and $48 \mathrm{hr}$. incubation.

In transductions between arabinose fermenting $\left(\mathrm{ara}^{+}\right)$and arabinose nonfermenting (ara-9) stocks, the clones were tested for their ability to ferment arabinose by streaking on EMB agar.

\section{THE GENETIC DIVERSITY OF THE MUTANTS}

When spontaneous mutations of leu-I 5 I to leucine independence are selected by plating large numbers $\left(\mathrm{IO}^{8}-\mathrm{IO}^{9}\right)$ of leu-I $5^{\mathrm{I}}$ bacteria on EMM, the resulting clones are of three types. For convenience these have been called fast, slow and unstable, and are distinguishable by their growth when subcultured on media with and without leucine (Smith-Keary, I958). Both the fast and slow types are stable; the unstable type is characterised by a very high rate of reversion to auxotrophy and will not be considered further in this paper.

When synthetic liquid minimal media was inoculated with bacteria from a 24-hour slope, the fast and wild types each had a lag phase of 180 minutes followed by logarithmic growth with a doubling time of 46 minutes. The slow type had a lag phase of $240-300$ minutes 
and a doubling time during the logarithmic growth of $7 \mathrm{I} \cdot 4$ minutes. The cultures were grown at $37^{\circ}$ with aeration.

Phage raised on the fast and slow growing types was used to infect the auxotroph $l e u-15 \mathrm{I}$ and transductions to prototrophy selected by plating on EMM. The results of these transductions for two different experiments are given in table I. The fast and slow type donors yielded only fast and slow type transductional clones respectively; these are phenotypically similar to the fast and slow type clones arising by spontaneous mutation from leu-I $5 \mathrm{I}$. The fast and slow characters are transduced at different frequencies. In this and in subsequent experiments the frequency of transduction, expressed as the number of transductions per $10^{8}$ survivors, was calculated from the formula

$$
t=\mathrm{Ioo}\left(\frac{n}{p y}-\frac{m}{q z}\right)
$$

TABLE I

Transduction of leu-I $5 \mathrm{I}$ to the fast and slow types

\begin{tabular}{|c|c|c|c|c|c|c|c|c|}
\hline Expt. & Donor & $\begin{array}{c}\mathrm{I} \\
\\
\text { Bacteria } \\
\text { plated } \\
\times \mathrm{IO}^{-7}\end{array}$ & $\begin{array}{c}2 \\
\begin{array}{c}2 \\
\text { Percentage } \\
\text { of } \\
\text { survivors }\end{array}\end{array}$ & $\begin{array}{c}3 \\
\text { Trans- } \\
\text { ductions }+ \\
\text { spontaneous } \\
\text { mutations } \\
\text { observed }\end{array}$ & $\begin{array}{c}4 \\
\text { Spontaneous } \\
\text { mutations/ } \\
\text { I0 } \\
\text { survivors }\end{array}$ & $\begin{array}{c}5 \\
\text { Trans- } \\
\text { ductions/ } \\
\text { I } 0^{8} \\
\text { survivors }\end{array}$ & $\begin{array}{c}6 \\
\\
\text { Clones } \\
\text { tested }\end{array}$ & $\begin{array}{l}\quad 7 \\
\text { Types of } \\
\text { clones } \\
\text { tested }\end{array}$ \\
\hline A & $\begin{array}{l}\text { fast } \\
\text { slow }\end{array}$ & $\begin{array}{l}7 \\
7\end{array}$ & $\begin{array}{l}20 \cdot 7 \\
22 \cdot 8\end{array}$ & $\begin{array}{l}690 \\
229\end{array}$ & $\begin{array}{l}7 \cdot I \\
7 \cdot I\end{array}$ & $\begin{array}{l}475 \mathrm{I} \cdot 9 \\
\mathrm{I} 423 \cdot 9\end{array}$ & $\begin{array}{l}3^{\circ} \\
3^{\circ}\end{array}$ & $\begin{array}{l}\text { all fast } \\
\text { all slow }\end{array}$ \\
\hline B & $\begin{array}{l}\text { fast } \\
\text { slow }\end{array}$ & $\begin{array}{l}4 \cdot 76 \\
4 \cdot 76\end{array}$ & $\begin{array}{l}16 \cdot 8 \\
11 \cdot 2\end{array}$ & $\begin{array}{l}428 \\
\text { I } 53\end{array}$ & $\begin{array}{l}5 \cdot 8 \\
5 \cdot 8\end{array}$ & $\begin{array}{l}5344 \cdot 2 \\
2848 \cdot 2\end{array}$ & $\begin{array}{l}3^{\circ} \\
3^{\circ}\end{array}$ & $\begin{array}{l}\text { all fast } \\
\text { all slow }\end{array}$ \\
\hline
\end{tabular}

where $t$ is the number of transductions per $10^{8}$ survivors, $n$ and $m$ are the observed numbers of clones on the transduction and control plates, $p$ and $q$ are the percentages of survival of the transduction mixture and the control, and $y$ and $z$ are the numbers of bacteria $\times 10^{-8}$ plated in the transduction and the control.

These results suggest that the fast and slow types are genetically different and that the slow type is not due to either a cytoplasmic factor or to a non-genetic difference.

\section{THE GENETIC MODELS}

Since the fast type, whether obtained by transduction or by spontaneous mutation, is indistinguishable from the wild type it is reasonable to interpret it as being due to a true backmutation of leu-I 5 I to wild type. Three models are possible to explain the slow type reversions:(I) there has been a mutation at the leu-I 5I site to an allele other than leu+ $u^{+}$(2) there has been a mutation at a second locus (i.e. a suppressor 
mutation) which enables the requirement for leucine to be partially overcome; (3) the slow type carries the leut allele but an inhibitor is present which partially inhibits the synthesis of leucine. These alternatives are set out below, together with the inferred genetic constitutions of the auxotroph and the fast and slow types;

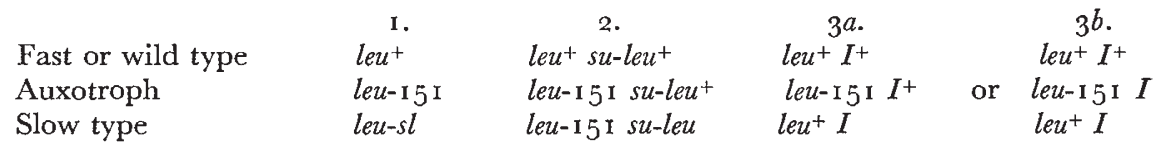

Models $3^{a}$ and $3^{b}$ are unlikely since a double mutation is required for $l e u-15$ I to mutate to the slow type $(3 a)$ or to the fast type $(3 b)$.

Provided that a fast growing type can be obtained from the slow type, either by mutation or by transduction, it should be possible to distinguish between models I and 2 by using the method devised by Yura (1956). If the suppressor hypothesis is correct, it should be possible to obtain a type with the genotype leu+ su-leu from the slow type either by mutation of $l e u-I_{5}{ }^{I}$ to $l e u^{+}$, or by transduction using wild type $\left(l e u^{+} s u\right.$-leu+ $)$ phage, provided that leu+ su-leu has a faster rate of growth on MM than has leu-I $5^{\text {I }}$ su-leu. By raising phage on leu ${ }^{+}$su-leu and using it to infect the auxotroph leu-I $5^{\text {I }}$ su-leu+, both $l e u^{+}$su-leu ${ }^{+}$ (fast) and leu-I5 su-leu (slow) clones should be recovered as a result of transduction of $l e u^{+}$and su-leu respectively, provided that the suppressor and leucine loci are not very closely linked. Alternatively, if model I is correct, only fast type clones would be recovered.

\section{THE GENETIC TESTS}

Attempts to isolate a fast growing type from the slow type by mutation were unsuccessful. Several clones were isolated which had a growth rate intermediate between that of the slow and fast types, but transduction experiments showed these to be genetically similar to the slow type.

An attempt was then made to produce the fast type (leu+ su-leu or $\left.l e u^{+}\right)$by transduction. Phage raised on a wild type donor was used to infect a slow type recipient and the transduction mixture spread on MM plates. After 24-hour incubation three of the largest transduced clones were picked off and subcultured; all had a growth rate similar to that of the fast type. These fast type clones will be referred to as fast' $^{\prime}$ I, 2 and 3 .

Phage was raised on each of these lysogenic fast' types; the preparations had a titre of approximately $\mathrm{IO}^{7}$ particles $/ \mathrm{ml}$. Care was taken to ensure that no potentially transducing phage was carried over from the phage inoculum by growing the phage on sensitive auxotroph bacteria immediately prior to growing it on the fast' types. Each of the preparations was used to infect a dilute suspension of the auxotroph leu-I 5 and transductions to prototrophy selected by plating on EMM. The results of these experiments are given in 


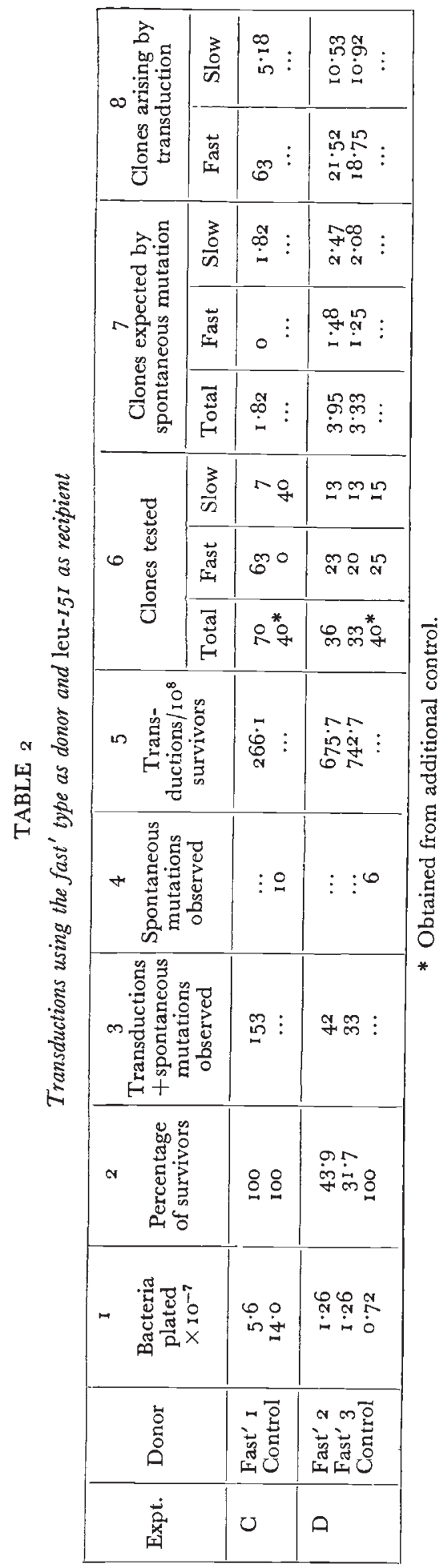

\begin{tabular}{|c|c|c|c|c|}
\hline \multirow{2}{*}{ 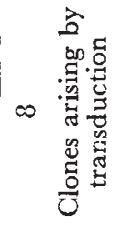 } & $\frac{3}{0}$ & $\stackrel{\infty}{\infty} \vdots$ & $\vec{\phi}:$ & ० $\vdots$ \\
\hline & $\overrightarrow{\vec{y}}$ & $\stackrel{\sim}{\alpha}$ & 足 & $\stackrel{\circ}{\vdots}$ \\
\hline \multirow{3}{*}{ 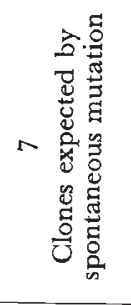 } & $\frac{3}{0}$ & $\underset{0}{1}:$ & $\stackrel{9}{0}:$ & $\circ \vdots$ \\
\hline & 莺 & 。 & के & 。 \\
\hline & 蹗 & $\stackrel{\overbrace{}}{6}:$ & $\tilde{\omega}$ & $0 \vdots$ \\
\hline \multirow{3}{*}{ 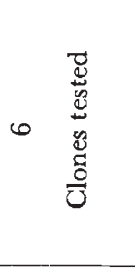 } & $\stackrel{3}{0}$ & $\stackrel{\sim}{\sim}$ & న్ల & 00 \\
\hline & 䓫 & $\stackrel{\sim}{\circ}$ & $\infty_{\sim}^{\infty}$ & 웅 \\
\hline & 胥 & $\stackrel{*}{*} \stackrel{\circ}{q}$ & $\stackrel{*}{*} \stackrel{+}{q}$ & $q^{\circ}$ \\
\hline \multicolumn{2}{|c|}{ 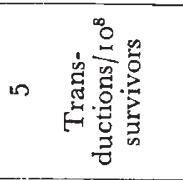 } & 妾: & 管: & $\begin{array}{l}0 \\
\dot{d} \\
\dot{m}\end{array}$ \\
\hline \multicolumn{2}{|c|}{ 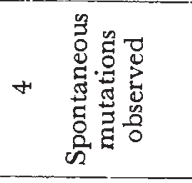 } & $\vdots \stackrel{m}{\text { ๙ }}$ & $\vdots \approx$ & $\vdots 0$ \\
\hline \multicolumn{2}{|c|}{ 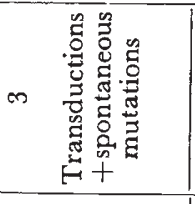 } & \&: & $8 \vdots$ & $\mathscr{q}:$ \\
\hline \multicolumn{2}{|l|}{ 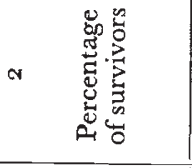 } & $\dot{\mathscr{\theta}}_{8} 8$ & $\begin{array}{l}\dot{\circ} \\
\dot{\circ}\end{array}$ & $\overrightarrow{\dot{\phi}} 8$ \\
\hline \multicolumn{2}{|l|}{ 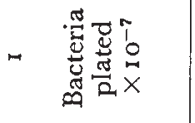 } & $\begin{array}{l}\infty \\
\stackrel{0}{0} \\
\dot{\varphi} \\
\dot{\varphi}\end{array}$ & 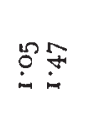 & $\begin{array}{l}00 \\
\text { के }\end{array}$ \\
\hline \multicolumn{2}{|l|}{ 离. } & 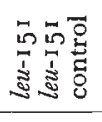 & 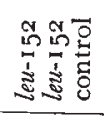 & 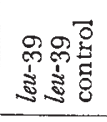 \\
\hline \multicolumn{2}{|l|}{ 苍 } & 되 & [工 & 0 \\
\hline
\end{tabular}


table 2. In each experiment there is an excess of both the fast and slow type clones over the number expected by spontaneous mutation (table 2, col. 7). These can only have arisen by transduction and so the suppressor hypothesis is confirmed. Hence the genetic constitution of the auxotroph is leu-I $5^{\mathrm{I}} s u-l e u-\mathrm{I}^{+}$, the slow type is leu-I5 $5^{\mathrm{I}} s u-l e u-\mathrm{I}$, the fast type is $l e u^{+} s u-l e u-\mathrm{I}^{+}$and the fast' type is leu ${ }^{+} s u-l e u-\mathrm{I}$.

\section{THE SPECIFICITY OF THE SUPPRESSOR su-leu-1}

Three leucine auxotrophs were tested in combination with su-leu-I; $l e u-151$ and $l e u-152$ (independently isolated from $m e A-22 \operatorname{try} B-2$ ) and leu-39. In reciprocal transductions between $l e u-\mathrm{I} 5^{\mathrm{I}}$ and $l e u-\mathrm{I} 5^{2}$ the yield of prototrophic clones was of the same order as when the recipients were treated with homologous phage, and not in excess of the number expected by spontaneous mutation. Thus leu-I $5^{1}$ and leu- 152 are

\section{TABLE 3}

Number of prototroph clones per $10^{8}$ survivors arising in transductions between leu-15I, leu-I52, leu-39 and the wild type

\begin{tabular}{|c|c|c|c|c|}
\hline Donor & leu-151 & leu-1 52 & leu-39 & WT \\
\hline Recipient & & & & \\
\hline$l e u-15 \mathrm{I}$ & $6 \cdot 2$ & $7 \cdot 8$ & 415 & 4758 \\
$l e u-\mathrm{I} 52$ & $5 \cdot 9$ & $7 \cdot 2$ & 309 & 3488 \\
leu-39 & $36 \cdot 2$ & 276 & 0 & 3816 \\
\hline
\end{tabular}

either identical alleles or mutants at very closely linked sites. In reciprocal transductions between $l e u-15 \mathrm{I}$ or $l e u-\mathrm{I} 5^{2}$ and $l e u-39$ the frequency of prototrophic clones was much higher than could be accounted for by spontaneous mutation, but lower than when phage raised on wild type bacteria was used (table 3). No cross-feeding occurred between leu-I $5^{\mathrm{I}}$ and leu-39. Hence leu-I $5^{\mathrm{I}}$ or $l e u-\mathrm{I} 5^{2}$ and leu-39 are probably mutants at linked but different sites of the same leucine locus.

When phage raised on fast' 2 (leu+ su-leu-I) was used to infect $l e u-15^{1}$ and $l e u-15^{2}$ an excess of both fast and slow type clones over the number expected by spontaneous mutation was obtained. When leu-39 was similarly infected only fast clones were recovered (table 4). su-leu-I is therefore allele specific. That both leu-I $5^{1}$ and $l e u-15^{2}$ are suppressed by su-leu-I is further evidence that they are identical alleles.

\section{THE ORDER OF THE GENETIC MARKERS}

Since the leucine and arabinose loci are linked (Demerec et al., I958) the position of $l e u$ - I 5 I relative to $l e u-39$ and ara-9 could be determined by using ara-9 and $\mathrm{ara}^{+}$as unselected markers in reciprocal 
transductions between $l e u-15^{\mathrm{I}}$ arat and leu-39 ara-9, selecting for leucine independence. The resulting clones were streaked on EMB agar to determine whether they were arat or ara-9. Table 5 shows the percentages of $\mathrm{ara}^{+}$and $a r a-9$ clones among the leucine independent clones from the transductions leu-I $5^{\mathrm{I}}$ ara $^{+}(\times)$leu-39 ara-9, leu-39 ara- $9(\times)$ leu-I $5^{\mathrm{I}} \mathrm{ara}^{+}$and leu-39 $\mathrm{ara}-9(\times) \mathrm{leu}^{+} \mathrm{ara}^{+}$.

Table 6 shows the regions of the recipient chromosome and the transduced fragment in which crossing over must occur in order to give $a r a^{+}$and ara-9 leucine independent clones in the transductions leu-39 $\operatorname{ara-9}(\times)$ leu-I $5_{\text {I }}$ rra $^{+}$and leu-I $5^{\text {I }} \operatorname{ara}^{+}(\times)$leu-39 ara-9, for each of the three possible orders of the markers (I) leu-39 leu-I5 I ara-9, (2) leu-I 5 I leu-39 ara-9, and (3) leu-I5I ara-9 leu-39.

If the order were leu-39 leu-I $5^{\text {I }}$ ara-9, the transduction leu-39 ara-9 $(\times)$ leu-I5 I $\mathrm{ara}^{+}$would yield $\mathrm{ara}^{+}$clones only as a result of quadruple

TABLE 5

Results of transductions between leu-I5I ara ${ }^{+}$, leu-39 ara-9 and wild type

\begin{tabular}{|c|c|c|c|c|c|c|c|}
\hline Expt. & Transduction & $\begin{array}{c}\mathrm{I} \\
\text { leu+ clones } \\
\text { per } 10^{8} \\
\text { survivors }\end{array}$ & $\begin{array}{c}2 \\
\qquad \\
\text { Clones } \\
\text { tested }\end{array}$ & $\begin{array}{c}3 \\
\text { Clones } \\
\text { ara }^{+}\end{array}$ & $\begin{array}{c}4 \\
\text { Clones } \\
\text { ara-9 }\end{array}$ & $\begin{array}{c}5 \\
\text { Percentage } \\
\text { of clones } \\
\text { ara }^{+}\end{array}$ & $\begin{array}{c}6 \\
\text { Percentage } \\
\text { of clones } \\
\text { ara }-9\end{array}$ \\
\hline $\mathrm{H}$ & $l e u-15 \mathrm{I}$ ara $^{+}(\times)$leu-39 ara -9 & 255 & 194 & 190 & 4 & $97 \cdot 9$ & $2 \cdot 1$ \\
\hline$x$ & $l e u-39$ ara-9 $(\times)$ leu-15 I ara $^{+}$ & 256 & 160 & 99 & 61 & $61 \cdot 9$ & $3^{8 \cdot 1}$ \\
\hline$J$ & leu-39 ara-9 $(\times)$ leu $^{+}$ara $^{+}$ & 2949 & 160 & 109 & $5 \mathrm{I}$ & 68. I & $31 \cdot 9$ \\
\hline
\end{tabular}

crossing over, and a large deficiency of this class would be expected compared with the frequency of $a r a^{+}$clones which arise when wild type bacteria are used as the donor strain. Such a deficiency was not found.

If the order were leu-I 5 I leu-39 ara-9, ara-9 clones from the transduction leu-I5I $\operatorname{ara}^{+}(\times)$leu-39 ara-9 could only arise by quadruple crossing over, and a large excess of ara $^{+}$clones would be expected. This is in agreement with the observation that 97.9 per cent. of the clones were $a r a^{+}$. If the order were leu-I $5^{\text {I }}$ ara-9 leu-39 this excess of ara $^{+}$clones could only be accounted for if ara-9 and leu-39 were very closely linked and nearly always jointly transduced. That this is not so is evident from the transduction leu-39 ara-9(X)leu ${ }^{+} \mathrm{ara}^{+}$, in which $3^{\prime} \cdot 9$ per cent. of the leucine independent clones were ara-9. Furthermore, it is most improbable that the ara locus is between what are believed to be two alleles of leu.

When leu-39 ara-9 bacteria were transduced with phage raised on the slow type leu-I 5 I su-leu- I $a r a^{+}$, both fast and slow type clones were recovered. $55^{\cdot} 7$ per cent. of these slow type clones were $\operatorname{ara}^{+}$(table 7 ). Since su-leu-I is specific for leu-I $5^{\mathrm{I}}$ the $a r a^{+}$slow type clones can only 
have arisen by the simultaneous transduction and incorporation of leu-I5I, leu-39+, su-leu-I and $a r a^{+}$, and su-leu-I must be linked to the leu and ara loci. The position of su-leu-I relative to leu and ara loci can now be determined.

If the ara locus were between $l e u$-I 5 I and su-leu-I, all the slow type clones would be $a r a^{+}$, except for a small number arising by quadruple crossing over. $44: 3$ per cent. of the slow type clones were ara-9, so that the order of the markers is not leu-I 5 I leu-39 ara-9 su-leu-1. In 55.7 per cent. of the transductions of su-leu-1, $a r a^{+}$is also transduced; in $68 \cdot 1$ per cent. of the transductions of $l e u^{+}$, ara $a^{+}$is also transduced. Hence it is probable that su-leu-I is farther from the ara locus than is the leu locus, and the most likely order of the markers is su-leu-I leu-I $5^{\text {I }}$ leu-39 ara-9.

This order was confirmed by testing nine of the fast type clones from the transduction leu-39 ara-9(X)leu-I 5 I su-leu-I ara ${ }^{+}$to determine which of the alleles su-leu-I and su-leu+ they carried. Table 8 indicates the regions of the bacterial chromosomes in which crossovers must occur in order to give each of the four possible types of fast clones, leu ${ }^{+}$ su-leu-I ara-9, leu+ su-leu-I ara+, leu ${ }^{+}$su-leu+ ara-9 and leu ${ }^{+}$su-leu+ ara ${ }^{+}$.

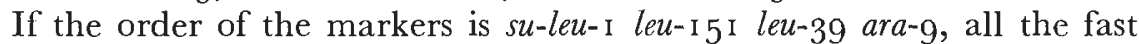
type clones should carry su-leu+ except for those arising by rare quadruple crossing over. If the order is leu-I $5^{\mathrm{I}}$ leu-39 su-leu-I ara-9 all the fast type $a_{r a}^{+}$clones will carry su-leu-I, and the fast type ara-9 clones either su-leu-I or su-leu+, whilst if the order leu-I5 I leu-39 ara-9 su-leu-I is correct, all the ara-9 fast type clones will carry su-leu+ and the $a^{+} a^{+}$ fast type either $s u$-leu-I or su-leu+.

Phage was raised on six fast type $a^{+} a^{+}$and three fast type ara-9 clones and used to infect the auxotroph leu-I5I. In none of the transductions was there an excess of the slow type over the number expected by spontaneous mutation. Hence all of the nine fast type clones carry the wild type suppressor allele. This result can only be

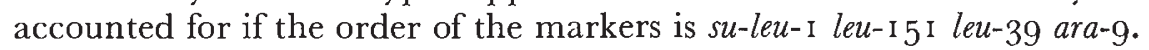

\section{DISCUSSION}

The occurrence of suppressor mutations in Salmonella typhimurium was first demonstrated by Yura (I956) who showed that two sizes of mutant colonies appeared when the adenine-thiamine mutant ath $A-2$ was plated on enriched minimal medium. The large colonies arose by back mutation at the ath $A$ locus while the small colonies arose by mutation at another, suppressor, locus. Mutations at this second locus (su-ath-I) specifically suppressed ath $A-2$ and its identical allele ath $A$-I . $\mathrm{He}$ also demonstrated the existence of a second suppressor mutation (su-ad-I) which was specific for the adenine mutant $a d C$-I I.

Similarly Howarth (1958) detected suppressors of cystine mutants. Five independent occurrences of suppressor mutations in mutants of the cys $A$ and cys $F$ loci, were each shown to suppress all known mutants 

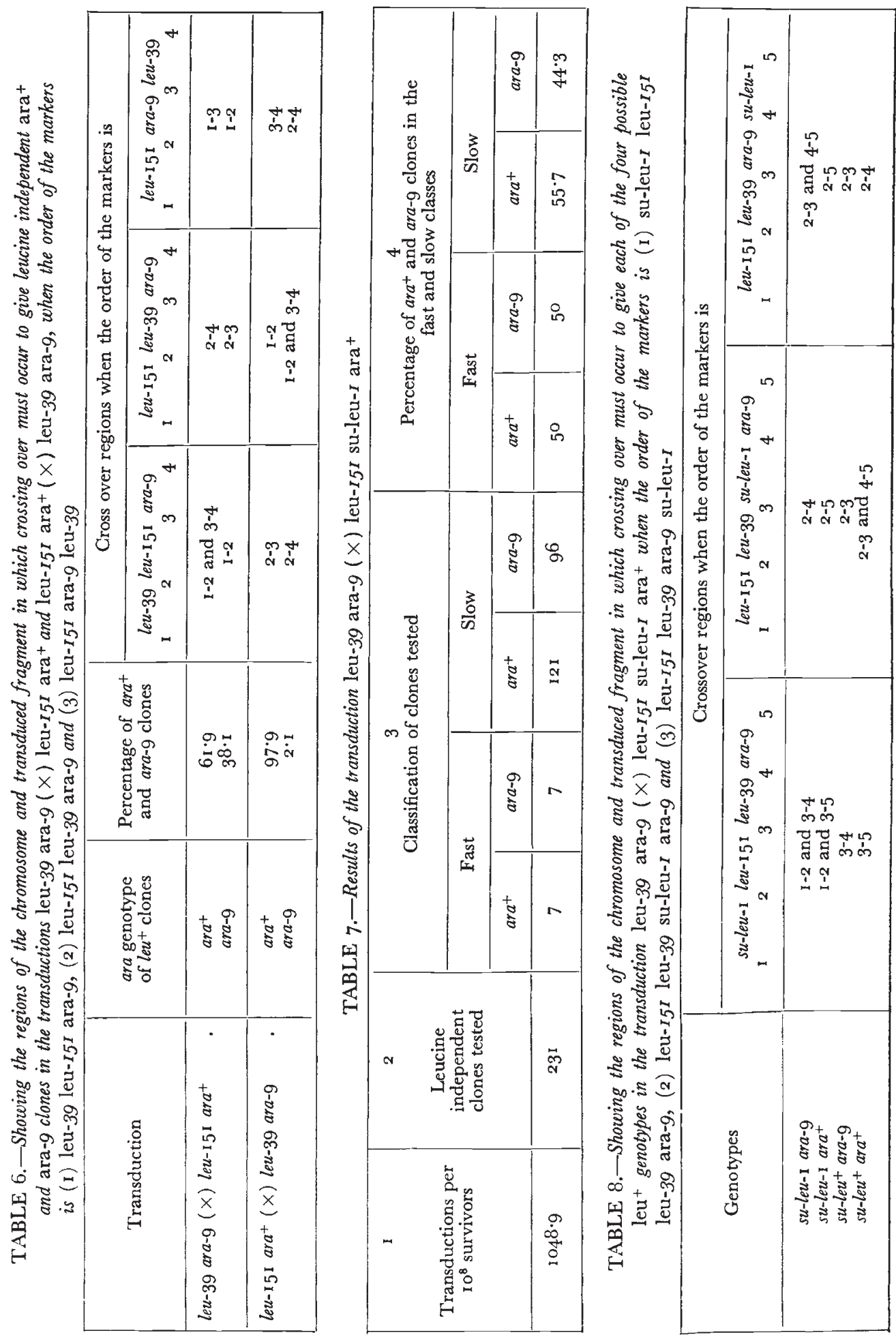
of these loci. These suppressors, which may be independent isolations of the same suppressor mutation, were not simultaneously transduced with $c y s A$ and cys $F$ markers, and there is no evidence that they are linked to this region of the chromosome.

The present work demonstrates the existence of a suppressor su-leu-I which suppresses the leucine mutant leu-I5I and its presumed identical allele leu-I 52, but which does not suppress leu-39. That this suppressor is linked to the leu and ara loci is indicated by the many simultaneous transductions of su-leu-I, leu-I $5^{\mathrm{I}}$ and $\mathrm{ara}^{+}$in the transduction leu-39 ara-9(X)leu-I5I su-leu-I ara ${ }^{+}$. On the other hand, $s u$-leu-I and leu cannot be very closely linked, or, as Yura (1956) has pointed out, only su-leu+leu+ fast type clones would have been recovered from the transduction $s u$-leu-I leu-I $5 \mathrm{I}(\times) s u-l e u^{+} l e u^{+}$. Of the three fast ${ }^{\prime}$ colonies analysed, fast' 2 and fast' 3 are undoubtedly su-leu-I leu${ }^{+}$, and fast' I probably is.

su-leu is believed to be the first instance of a suppressor in a microorganism which has been shown to be linked to the gene that it suppresses.

Suppressors, differing widely in their degree of specificity, have also been described in Neurospora crassa. Yanofsky (I952) and Yanofsky and Bonner (1955a) have described four suppressors which act by partially restoring tryptophane synthetase activity in mutants lacking this enzyme. One suppressor, $S-2$ is allele specific for $t d^{2}$, the other three being able to suppress more than one $t d$ allele. They have also demonstrated that four specific suppressors of $t d^{2}$ are due to suppressor mutations at, at least, three separate loci (Yanofsky and Bonner, I955b). Giles and Partridge (I953) have described a suppressor of inositolless which is also allele specific. Unspecific suppressors have been described by Lein and Lein (1952), Giles (I95I), Mitchell and Mitchell (1952) and Strauss and Pierog (1954). None of these suppressors has been shown to be linked to the locus it suppresses.

The mode of action of su-leu-I has not been analysed biochemically, but since it is allele specific it is improbable that it acts by opening up an alternative synthetic pathway. Such a mechanism has been proposed by Howarth (1958) for the unspecific suppressors of cystine mutants, and has been shown to be responsible for the suppression of acetate requirement in $\mathcal{N}$. crassa (Strauss and Pierog, I954). su-leu-I probably acts by one of the mechanisms proposed by Gots (1956) for the suppressor of adenine requirement in $S$. typhimurium-namely by either restoring the activity of an inactive enzyme, or by removing an enzyme inhibitor.

\section{SUMMARY}

I. A slow growing " reversion" of leu-I5 I in Salmonella typhimurium has been analysed by transduction and shown to be due to a suppressor mutation, su-leu-I.

2. su-leu-I is specific for $l e u-\mathrm{I}_{5} \mathrm{I}$ and its probably identical allele $l e u$-I $5^{2}$, and has no effect in combination with leu-39. 
3. su-leu-I is linked to leu and to ara.

4. Using ara-9 as an unselected marker the order of the markers has been shown to be $s u$-leu-I $\left(\begin{array}{l}l e u \text {-I } 5 \text { I } \\ l e u \text {-I } 5^{2}\end{array}\right)$ leu-39 ara-9.

Acknowledgments. - I wish to acknowledge the receipt of a Training Grant, and later a Fellowship, from the Medical Research Council of Ireland. I am indebted to Mr G. W. P. Dawson for his many suggestions and for his help in preparing this manuscript.

\section{REFERENCES}

ADAMs, M. H. 1950. Methods of study of bacterial viruses. In Methods in Medical Research, vol. 2, ed. J. H. Comroe, Jr. The Year Book Publishers Inc., Chicago, pp. I-73.

DEMEREC, M. 1956. Terminology and nomenclature. In Genetic Studies with Bacteria, Carnegie Inst. Wash. Pub., 6I2, I-4.

DEMEREG, M., LAHR, E. L., MIYAKE, T., GOLDMAN, I., BALBINDER, E., BANIČ, S., HASHIMOTO, K., Glanville, E. v., AND Gross, J. D. 1958. Bacterial genetics. Carnegie Inst. Wash. Year Book, 57, 390-406.

GILES, N. H. I95I. Studies on the mechanism of reversion in biochemical mutants of Neurospora crassa. Cold Spring Harbor Symp. Quant. Biol., $16,283-313$.

GILES, N. H., AND PARTRIDGE, c. W. H. 1953. The effect of a suppressor on allelic inositolless mutants in Neurospora crassa. P.N.A.S., 39, 479-488.

GOTs, J. s. 1956. The biochemical nature of a suppressor mutation in a purine requiring mutant of Salmonella typhimurium. In Genetic Studies with Bacteria, Carnegie Inst. Wash. Pub., 6x2, 87-96.

HOWARTH, s. 1958. Suppressor mutations in some cystine-requiring mutants of Salmonella typhimurium. Genetics, 43, 404-418.

LEIN, J., AND LEIN, P. S. I952. Studies on a suppressor of non-allelic acetate-requiring mutants in Neurospora. P.N.A.S., $3^{8,} 44^{-48 .}$

MTTGHELl, M. B., AND MITCHELL, H. K. 1952. Observations on the behaviour of suppressors in Neurospora. P.N.A.S., 38, 205-2 I4.

SMITH-KEARY, P. F. 1958. An unstable mutation in Salmonella typhimurium. Nature, $18 x, \mathrm{I} 672$.

STRAUSS, B. S., AND PIEROG, s. I954. Gene interactions; the mode of action of the suppressor of acetate-requiring mutants of Neurospora crassa. 7. Gen. Microbiol., Io, $221-235$.

YURA, T. 1956. Suppressor mutations in purine requiring mutants of Salmonella typhimurium. In Genetic Studies with Bacteria, Carnegie Inst. Wash. Pub., 612, 63-75.

YANOFSKY, c. I952. The effects of gene change on tryptophane desmolase formation. P.N.A.S., 38, 21 5-226.

YANOFSKY, G., AND BONNER, D. M. 1955a. Gene interaction in tryptophane synthetase formation. Genetics, 40, 761-769.

YANOFSKY, G., AND BONNER, D. M. 1955b. Non-allelic suppressor genes affecting a single $t d$ allele. Genetics, $40,602-603$ (abstract). 